\title{
The Basics of Stellites in Machining Perspective
}

\author{
Md Shahanur Hasan', Md Abdul Mazid², and Richard E. Clegg ${ }^{3}$
}

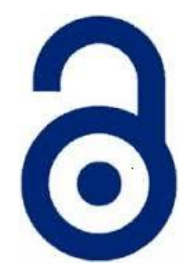

\author{
Received: 28 October 2016 \\ Accepted: 24 November 2016 \\ Published: 20 December 2016 \\ Publisher: Deer Hill Publications \\ (c) 2016 The Author(s) \\ Creative Commons: CC BY 4.0
}

\begin{abstract}
Stellites are cobalt (Co)-based superalloys available in two main combinations: (a) a Tungsten (W) group with composition of Co-Cr-W-C, and (b) a Molybdenum (Mo) group containing Co-Cr-Mo-C. Stellites possess outstanding corrosion resistance, oxidation resistance, wear resistance, heat resistance, and low magnetic permeability. Components made of stellites work well in highly corrosive environments and maintain these advantageous properties at elevated temperatures. Components made of stellites are widely used in the oil and gas, automotive, nuclear power, paper and pulp, chemical and petrochemical, refineries, automobile, aerospace and aircraft industries. By virtue of their nonmagnetic, anticorrosive and non-reactivity to human body-fluid properties, stellites are used in medical surgery and in surgical tools, tooth and bone implants and replacements, heart valves, and in heart pacemakers. The hardness range of stellites is from 32 to $55 \mathrm{HRC}$, which makes stellites brittle materials but they have a low Young's modulus. Due to their high hardness, dense but non-homogeneous molecular structure and lower thermal conductivity, machining operations for parts made of stellites are extremely difficult, categorising stellites as difficult-to-machine materials like Ti-alloys, inconels, composites and stainless steels. Usually, machine components made of stellites are produced by a deposition method onto steel substrates instead of expensive solid stellite bars. The rough surfaces of deposited stellites are then finished by grinding, rather than some other economic machining process, which is costly and time-consuming, making stellite products very expensive. This paper provides a basic overview of stellites applicable in engineering, their significances and specific applications, advantages and disadvantages in respect of machining processes. A brief review on experimental research on economically rational cutting parameters for turning operations of Stellite 6 using coated carbide inserts is presented in this paper. Interesting facts on the residual stresses induced by machining processes in Stellite 6 are revealed and analysed. The microhardness variation of machined surfaces of stellite 6 using different tool geometries is investigated in this research review. It is revealed that coated carbide inserts with a medium-size nose radius perform better in respect of hardness changes and heat generation, producing minimum phase changes on machined surfaces of stellite 6.
\end{abstract}

Keywords: Cobalt alloys; stellites; difficult-to-machine; residual stress; surface roughness; surface integrity; manufacturing processes.

\section{INTRODUCTION}

The machinability of a material largely depends on its physical, chemical and metallurgical characteristics. Consequently the surface integrity (residual stress distribution, microhardness, phase changes, plastic deformation, micro-cracking, tears and laps related to built-up-edge formation) and surface topology (surface roughness and waviness) of machined parts are directly determined by these characteristics, as well as by the machining regimes/parameters selected, machine tool dynamics, cutting-tool material and geometry, and cooling fluid. As revealed, out of these variables, adequate and optimal cutting parameter selection plays the most significant role. The major quality assurance of machined parts checks geometric accuracy, surface roughness and residual stress levels of the machined parts. All these parameters and the factors related to surface integrity are largely dependent on the selected cutting regimes for machining a given material using a given cutting tool on a certain machine tool.

Hasan, M. S.'. 网, Mazid, M. A. ${ }^{2}$, and Clegg, R. E. ${ }^{3}$

IScience and Engineering Faculty, Queensland University of Technology, Brisbane, Australia

${ }^{2}$ School of Engineering and Information Technology, Federation University, Gippsland, Australia

35 chool of Engineering and Technology, Central Queensland University, Rockhampton, Australia

E-mail: m2.hasan@qut.edu.au 
Therefore researching for optimal cutting regimes/parameters for machining a certain material using certain cutting inserts is the topmost priority in machining research. All other research relevant to machining would be accurate and effective if the optimal cutting regimes have been used for machining the samples under investigation. Nevertheless, the selection of cutting regimes, the right cutting tools and adequate machine tools is the appropriate solution to the most economically effective and sustainable manufacturing.

At the same time, it is always more effective to know about the science of a material (in respect of chemistry, metallurgy, strength properties, application perspectives and motivation) prior to starting dealing with it, particularly in the case of its processing or designing. This paper deals with the basic but essential knowledge and information on stellites that would be helpful for researchers, scientists, engineers and professionals dealing with cobalt-based alloys, particularly in machining these and other superalloys.

\section{HISTORY OF STELLITES}

Stellites have an inspirational history since their origin. Elwood P. Haynes, known as one of the two first inventors who created the horseless cart for the first time in human history, in his laboratory, developed a number of cobaltbased metal alloys for producing various critical parts of internal combustion engines and for tougher lathe tools for machining his horseless cart's components and he named these alloys "stellites" in the 1900s [1]. Haynes derived this name from the Latin word "Stella" that stands for "Star" because of their star-like lustre. The hardness of these alloys is very high in relation to other metals and metal alloys; they possess high wear resistance, corrosion resistance and ability to maintain these extraordinary properties at extreme temperatures for long periods of time. Initially Haynes developed a nickel-chromium ( $\mathrm{Ni}-\mathrm{Cr}$ ) alloy and a cobalt-chromium ( $\mathrm{Co}-\mathrm{Cr}$ ) alloy and got these two superalloys patented in 1907. Following his subsequent research Haynes produced two new groups of cobaltbased alloys with the addition of tungsten (W) and molybdenum (Mo). He added these two new alloys under the group-name "Stellites" and these were patented in 1912. Haynes developed stellite alloys in his laboratory for producing new corrosion resistant and heat tolerant metals for automobile parts, dental instruments, surgery tools, sharp-edged tools, cutlery, metal machining tools, and many other applications requiring anticorrosion, high wear resistance, high hardness and heat tolerance for longer periods of time. Haynes was granted another patent in 1913 for development of another complex superalloy of cobalt-chromium-molybdenum-tungsten-carbon (Co-Cr-Mo-WC) known as Haynes alloy $6 \mathrm{~B}$.

Nowadays, many stellite alloys are produced with combinations of various amounts/proportions of cobalt, chromium, molybdenum, tungsten, titanium, nickel, iron, aluminium, carbon, boron, manganese, phosphorus, silicon and sulphur. By virtue of their low magnetic permeability and excellent anticorrosive properties some of the stellites are extremely suitable for medical surgery, dental implants, bone replacement, artificial heart valves, and heart pacemakers. Due to their high hardness and good ductility, highly dense molecular structure, harder and more regularly organised carbides, lower thermal conductivity, tendency to resist plastic deformation having lower Young's modulus, stellites and other cobalt-based alloys, like titanium alloys, are categorized as difficult-to-machine materials due to their poor machinability. The machinability of a material is defined by the surface roughness quality and the surface integrity obtained, the tool life, heat generation in the cutting zone, chip formation difficulties, material removal rate (MRR) and power consumption, machine tool dynamics, and other parameters involved in metal machining. Difficult-to-machine materials are materials which produce excessive tool wear, excessive cutting forces causing high heat generation, difficulties in chip formation resulting in poor surface finish during machining operations. One of the important phenomena in machining of difficult-to-machine materials is excessive heat generation in the cutting zone causing very high temperature growth in the primary and secondary shear zones which in turn causes phase changes in machined surfaces and the built-up-edge (BUE) causing, in turn, premature cutting-tool damage.

Due to the poor machinability of the Co-alloys most components made of these alloys are produced by precision casting, powder metallurgy and sintering, and finished by grinding and unconventional machining techniques (EDM, LBM, etc.) $[2,3,4,5]$. This leads to lower productivity and a high manufacturing cost of Coalloy components, especially for medical implants such as hip and dental implants.

\section{CHEMICAL COMPOSITION AND MECHANICAL PROPERTIES OF STELLITES}

Stellites are cobalt (Co)-based superalloys. Cobalt is a tough silver-grey metal of low magnetic permeability with a faint bluish tinge. Cobalt appears in a $\mathrm{CPH}$ structure at below $421^{\circ} \mathrm{C}$, and above this temperature it appears in a FCC crystal lattice structure. Cobalt has a high radioactive Curie point/temperature $\left(1121^{\circ} \mathrm{C}\right)$ and it possesses a high damping characteristic due to its ductility. These properties make cobalt a useful ingredient/inclusion for alloys subjected to vibration and to high temperature $[2,3,6]$. Cobalt exists in 26 isotopes ranging from Co-50 to Co-75. Co-59 is the only stable isotope amongst them. Cobalt has a magnetic permeability about $2 / 3$ of that of iron, making cobalt alloys the second best non-magnetic biomaterials following Ti-alloys. The density of cobalt is 8.90 $\mathrm{gm} / \mathrm{cc}$ and the atomic mass is $58.9332 \mathrm{amu}$. The melting point of cobalt is $1495^{\circ} \mathrm{C}$ [6]. All of these attributes are advantageously used in enhancing the properties of stellites (Co-alloys). Addition of cobalt to metal cutting tool materials contributes to a lower friction coefficient in the cutting zone (interaction of cutting tool and work-piece material) and it helps to maintain red hardness. Cobalt-based alloys are useful in applications requiring higher corrosion resistance, wear resistance, high strength at elevated temperature, and they perform well in aggressive 
chemical environments. Stellites are also applicable in areas where high creep resistance, structural stability, resistance to thermal creep and resistance to thermal corrosion are required [2, 4, 7, 8]. As mentioned earlier, currently two main combinations of stellites are available. W-containing Co-Cr-W-C combinations: such as Stellite 6, Stellite 12, Stellite 1 and Stellite 190, and Mo-containing Co-Cr-Mo-C combinations: such as Stellite 706, Stellite 712, Stellite 701 and Stellite $790[6,9]$.

A higher percentage of chromium $(\mathrm{Cr})$ in them provides stellite alloys with high corrosion and wear resistance at high temperatures and good magnetic properties. Chromium acts as a carbide former and is a most important strengthening element in the alloy matrix. Chromium also provides the alloys with excellent corrosion resistance and anti-oxidation. Tungsten (W) and molybdenum (Mo) are major elements of stellites which enhance the strength of the alloy matrix. Molybdenum contributes to improved hardness forming hard and stable carbides in alloys. Molybdenum itself has the sixth-highest melting point $\left(2623^{\circ} \mathrm{C}\right)$ in known materials. Tungsten (W) as an alloying element provides hardness with enough ductility, high density and high red hardness. Carbon provides alloys with a lower electrical conductivity but the highest thermal conductivity. Carbides in stellites provide high hardness and red hardness for alloys.

The formation of hard carbides in stellite alloys provides sliding wear and abrasion wear resistance and the chromium carbide $(\mathrm{Cr}-\mathrm{C})$ matrix provides resistance to galling, cavitations and corrosion. Stellites exhibit excellent metal-on-metal anti-galling behaviour [3]. Table 1 below shows the chemical composition of various grades of stellites while Table 2 shows the mechanical properties of some of the stellites available [6]. As Table 2 shows, the coefficient of elongation of Stellites 1, 6 and 12 is very low while those of Stellites 6B and 21 are high enough to suit various applications. Accordingly Stellites $6 \mathrm{~B}$ and 21 have relatively lower hardness and a higher percentage of elongation providing higher ductility, making them suitable for purposes requiring less brittleness, while these stellites are used as excellent biomaterials. Harder stellites, such as Stellite 6, are used for hard-facing slurry valves for uses in alumina refineries where the wear and corrosion rates are very high $[8,9,10,11]$. These valves need to be machined precisely in order to provide better matching of functional surfaces to prevent fluid leakage and to prevent excessive wear and corrosion in the valves. A better surface finish of machined surfaces also decreases the occurrence of corrosion and corrosion-based fatigue cracking.

The excellent properties of Co-alloys are attributed to the crystallographic nature of cobalt, the solid-solutionstrengthening effect of chromium ( $\mathrm{Cr}$ ) and molybdenum (Mo), the formation of extremely hard carbides and the corrosion and wear resistance imparted by chromium. Tungsten (W) in cobalt alloys provides high density creating high hardness and red hardness with substantial ductility as well as high heat tolerance. Molybdenum (Mo) in cobalt alloys promotes hard and stable carbides in alloys. As mentioned earlier, molybdenum itself has the sixthhighest melting point $\left(2,623^{\circ} \mathrm{C}\right)$ within the known metals.

Table 1: Chemical composition of stellites (weight \%)

\begin{tabular}{|l|l|l|l|l|l|l|l|l|l|l|}
\hline Trade name of alloy & Co & $\mathrm{Cr}$ & W & Mo & C & Fe & Ni & Si & Mn \\
\hline & Tungsten (W) containing \\
\hline Stellite 1 & 48.2 & 30 & 13 & $\ldots$. & 2.5 & 3 & 1.5 & 1.3 & 0.5 \\
\hline Stellite 4 & 46.43 & 30 & 14 & $\ldots$. & 0.57 & 3 & 3 & 2 & 1 \\
\hline Stellite 6 & 43.2 & 29 & 4.5 & $\ldots$. & 1.2 & 3 & 3 & 1.5 & 1 \\
\hline Stellite 12 & 47.4 & 30 & 8.3 & $\ldots$ & 1.4 & 3 & 1.5 & 0.7 & 2.5 \\
\hline Stellite 23 & Bal & 24 & 5 & $\ldots$ & 0.4 & 1 & 2 & 0.6 & 0.3 \\
\hline Stellite 31 & Bal & 25.5 & 7.5 & $\ldots$ & 0.5 & 2 & 10.5 & 1 & 1 \\
\hline Stellite 190 & Bal & 26 & 14.5 & $\ldots$. & 3.3 & 3 & 3 & 2 & 1 \\
\hline Stellite 306 & Bal & 25 & 2 & $\ldots$ & 0.4 & $\ldots$ & 5 & $\ldots$ & $\ldots$ \\
\hline Stellite F & Bal & 25 & 12.3 & $\ldots$. & 1.75 & 3 & 22 & 2 & 1 \\
\hline Stellite 6B & Bal & 30 & 4 & $\ldots$. & 1 & 3 & 25 & 0.7 & 1.4 \\
\hline & Molybdenum (Mo) containing & & & & & \\
\hline Stellite 712 & Bal & 29 & $\ldots$ & 9 & 1.8 & 2.5 & 2.5 & 1 & 0.5 \\
\hline Stellite 21 & Bal & 27 & $\ldots$ & 5.5 & 0.25 & 3 & 2.75 & 1 & 1 \\
\hline Stellite 27 & Bal & 25 & $\ldots$ & 5.5 & 0.4 & 1 & 32 & 0.6 & 0.3 \\
\hline
\end{tabular}

Table 2: Mechanical properties of stellites

\begin{tabular}{|c|c|c|c|c|c|c|c|}
\hline $\begin{array}{c}\text { Trade names } \\
\text { of alloys }\end{array}$ & $\begin{array}{l}\text { Density, } \\
\rho\left(\mathrm{g} / \mathrm{cm}^{3}\right)\end{array}$ & $\begin{array}{c}\text { Yield } \\
\text { Strength, } \\
\mathrm{S}_{\mathrm{y}}(\mathrm{MPa})\end{array}$ & $\begin{array}{l}\text { Ultimate } \\
\text { tensile } \\
\text { strength, } S_{\mathrm{ut}} \\
(\mathrm{MPa})\end{array}$ & $\begin{array}{c}\text { Melting } \\
\text { Range } \\
\left.\mathrm{T}^{\circ} \mathrm{C}\right)\end{array}$ & $\begin{array}{l}\text { Hardness } \\
\text { (HRC) }\end{array}$ & $\begin{array}{c}\% \\
\text { elongation }\end{array}$ & $\begin{array}{c}\text { Thermal } \\
\text { conductivity } \\
\lambda(\mathrm{W} / \mathrm{m} . \mathrm{K})\end{array}$ \\
\hline & \multicolumn{7}{|c|}{ Tungsten $(W)$ containing } \\
\hline Stellite 1 & 9.16 & $\ldots$ & 618 & 1255- & 55 & $<1$ & $\ldots$ \\
\hline
\end{tabular}




\begin{tabular}{|c|c|c|c|c|c|c|c|}
\hline & & & & 1290 & & & \\
\hline Stellite 6 & 8.9 & 541 & 896 & $\begin{array}{l}1285- \\
1395\end{array}$ & 40 & 1 & $\ldots$ \\
\hline Stellite 12 & 9 & 649 & 834 & $\begin{array}{l}1280- \\
1315\end{array}$ & 48 & $<1$ & ... \\
\hline Stellite 6B & 8.84 & 619 & 998 & $\begin{array}{l}1265- \\
1354\end{array}$ & 37 & 11 & 14.82 \\
\hline & \multicolumn{7}{|c|}{ Molybdenum (Mo) containing } \\
\hline Stellite 21 & 8.8 & 494 & 694 & $\begin{array}{l}1186- \\
1383\end{array}$ & 32 & 9 & 14.5 \\
\hline Stellite 712 & 8.7 & $\ldots$ & $\ldots$ & $\begin{array}{l}1128- \\
1236\end{array}$ & 48 & $\cdots$ & $\ldots$ \\
\hline
\end{tabular}

\section{INDUSTRIAL APPLICATIONS OF STELLITES}

The justification behind using stellites in engineering industry is to provide a corrosion-resistant and wear-resistant surface which will help combat the wear and corrosion of mechanical components. However, wear-resistant materials having a uniformly distributed, dense carbide matrix are naturally difficult to machine due to their high carbide content. In some cases non-homogeneous hard carbide distribution, lower heat conductivity, and high hardness contribute to poor machinability for these materials [11].

Cobalt-based alloys are sometimes non-magnetic, but high-strength materials. These alloys are renowned for their high wear, corrosion and heat resistance properties, possess high hardness but are ductile enough materials. These alloys nicely preserve their strength even at high temperatures for longer periods of time and they behave perfectly in corrosive and acidic environments. As mentioned earlier, cobalt-based alloys exhibit excellent resistance to degradation in the environment of human body fluid, which has led to their successful application in medical surgery and surgical implants. Several medical tests have proven $[1,3,9]$ that cobalt-based alloys are biocompatible and suitable for use as surgical implants and bone replacements. According to their applications the conventional Co-alloys may be categorised [7] as follows:

- Wear-resistant alloys,

- High-temperature alloys, and

- Corrosion-resistant alloys.

Stellite $6 \mathrm{~B}$ and Stellite $6 \mathrm{~K}$ fall within the group of wear-resistant alloys possessing a high proportion (about 30\%) of $\mathrm{Cr}$ and about $65 \%$ of $\mathrm{Co}$. The high proportion of $\mathrm{Cr}$ performs as the chief carbide former during alloy solidification, providing high strength. The excellent wear resistance for these alloys is attributed to the mostly uniform Co-rich matrix of formed carbide grains. By virtue of its excellent wear resistance and toughness Stellite 6 has been widely used in manufacturing of cutting bits for deep drilling equipment for mining purposes, rockcrushing rollers, cement and steel equipment, and conveyor systems, steam-turbine erosion shields, half sleeves and bushings where lubrication is inaccessible or effective lubrication is impossible. Stellite $6 \mathrm{~K}$, having in its composition no molybdenum (Mo) but $30 \%$ of $\mathrm{Cr}$ producing quite high hardness (47 HRC), is highly suitable for producing cutting knives for uses in cutting of soft organic materials and vegetation materials such as tobacco.

Another alloy, Stellite 3, containing 3 times as much tungsten $(W)$ as Stellites 6, 6B, and 6K, and having no Mo is inferior to Stellites $6,6 \mathrm{~B}$ and $6 \mathrm{~K}$ in corrosive environments and is not recommended for uses in such situations. But by virtue of a higher carbon (C) content giving an increased volume fraction of carbides, Stellite 3 is 3 to 4 times as wear-resistant as Stellite 6 and twice as resistant as Stellite 12. Stellite 3 has a higher red hardness and resists galling like all stellite alloys. Accordingly Stellite 3 is recommended for manufacturing bearing balls and needles, sleeves and bushings, valve seat inserts in non-corrosive environments, surgical scissor inserts, burner nozzles, steelmill guide rolls and seaming rolls.

Stellites are highly useful and popular representatives of cobalt-based alloy groups. By virtue of their abovementioned superior mechanical properties stellites have, as mentioned earlier, applications in many industries such as oil and gas, automotive, aerospace, pulp and paper, food processing, wood and timber, nuclear industries and in medical surgery for producing surgical tools and human bone/part replacements. Applications of stellites in various fields are summarized below industry-wise.

\section{Oil, Gas and Mining Industries}

Most mechanical components in the oil, mining and gas industry are subjected to combinations of corrosion, abrasion, high pressure, galling and high temperature. Cobalt-based alloys, such as Stellites 6, 12, 21 and 6B, provide superior wear and corrosion resistance, consequently longer component life. Wear-resistant stellites provide, it is said, peace of mind for oil, gas and mining exploration equipment manufacturers as well as for mineral explorers in the field [9]. The machine components made of Stellites 6, 12, 21 and 6B commonly used in oil and gas industries are listed below: 
- MWD (Measurement While Drilling) and LWD (Logging While Drilling) internal wear tools such as Rotors, Stators, Impellors, Centralisers, Erosion Inserts, Landing, Wear and Turbine Sleeves, Fishing Heads;

- Filter Screens;

- Kelly Valve Trim;

- Cages;

- Sucker Rod Couplings;

- Annular Blow-out Preventers;

- Balls and Seats;

- Subsurface Safety Valves (Flappers, Darts);

- $\quad$ Drilling heads.

As Tables 1 and 2 show, Stellites 6,12 and 6B are tungsten (W)-rich alloys exhibiting very low coefficients of elongation (for metals close to 1\%) and higher hardness ranging within 40-50HRC. Stellites 6 and 12 contain a high percentage of Chromium ( $\mathrm{Cr}$ ) making them highly wear and corrosion resistant and improving hardness. All these properties make machine components highly survivable in the situation of on-shore and off-shore oil and gas plants and in deep drilling sites.

\section{Chemical Refineries, Power and Petrochemical Industry}

Wear and corrosion problems are said to be plagues in refinery industries. Stellite 6 alloy solves this problem, giving longer life, reduced unplanned down time, and reduced maintenance expenditures. The major products made of Stellites 6 and 12 for refineries and petrochemical industries are a variety of nozzles, thermowells, valves, valve seats, valve slides and balls, valve plugs, valve trim, components of fluidised catalytic cracking units and pump components. Cast stellite pump casings and impellers exhibit maximum life. Nozzles of various sizes and shapes are used in refining and petrochemical processing plants for injecting and introducing high-pressure steam, compressed air and hydrocarbon and other chemicals. Air grid nozzles, reactor feed and other feed nozzles, regenerator air grid nozzles, steam stripping nozzles, orifice chamber nozzles are some of the nozzles made of stellites [9].

Nozzles are designed and produced to retain their structural and dimensional integrity over a period of planned time. Nozzles made of Stellites 6 and 12 exhibit maximum life. These two cobalt-based alloys, as Tables 2 and 3 suggest, contain in their composition about $30 \%$ of cobalt (Co) while the chromium ( $\mathrm{Cr}$ ) content is as high as $30 \%$ with a good percentage of tungsten (W). High proportions of $\mathrm{Co}$ and $\mathrm{Cr}$ in Stellites 6 and 12 contribute to the longer life span of nozzles in refineries.

Various parts of power generation plants which are subjected to high heat, such as fuel nozzles, bushes, seals and retainers, diaphragms, shields, blades, and other critical parts are made of cobalt and nickel-based alloys, since parts of power plants require protection against high heat, wear, corrosion and fatigue. Stellites 6 and 12 exhibit a very low coefficient of elongation (close to 1\%) and so Young's modulus as well providing high hardness, dense microstructure, and very high anticorrosive and wear-resisting capabilities, providing the required physicomechanical properties for many parts in power and petrochemical industries and refineries.

\section{Pulp and Paper Industry}

Stellite alloys like Stellites 6, 6B, 6K and Stellite 12, delcrome 90 solve some of the pulp and paper industries' toughest wear problems. Examples of components made of these cobalt alloys used in pulp and paper industries are plug screw feeders, black-liquor spray nozzles, palm guides, steam nozzles, feed roll points, bottom slitter brands, sleeves and bushing.

\section{Food Processing Industry}

Stellites are used in components in the food processing industry where high wear resistance and excellent corrosion resistance are the main requirements. Some examples of these products are various types of knobs, pins, bushes, plungers, cutlery, cooking ware, parts of food-processing machines and driver screws.

\section{Wood and Timber Industry}

Stellite-tipped disk-saw teeth give better surface finish and considerably longer operational times. Although the stellite has a lower hardness than cemented carbide, it has greater wear resistance and it is tough and ductile enough to withstand shock. The products used in conjunction with automatic, long-life saw-tipping equipment are triangular and rectangular tips, round balls, triangular and trapezoidal rods.

\section{Automotive Industry}

The history of stellites has a direct link to the automobile industry. As mentioned at the beginning of this review paper, stellites were first developed by Elwood P. Haynes for producing various critical parts of his innovative horseless cart in 1900 in a township called Kokomo in Indiana. He used his newly patented cobalt-chromium alloys for producing parts of his internal combustion engines. Haynes also found that some of these new cobalt alloys are more durable for lathe cutting tools than the stainless steels that he invented earlier [1]. Usually Stellite 6, Stellite 
$6 \mathrm{~B}$, Stellite 12 and Stellite $\mathrm{F}$ are used in automotive parts manufacturing nowadays and since the beginning of the twentieth century. Some of these automotive parts are pins, bushings, spacers, shafts, wear inserts, washers, camshafts, cam lobes, valves, valve stem tips, valve seats, produced by various processes like casting, investment castings, powder metallurgy and plasma transferred arc (PTA), and the thermal powder spray process is used for some parts $[11,12,13,14]$.

\section{Aerospace industry}

A variety of degradation problems exist in aircraft engines as a result of metal-to-metal wear, fretting, hot corrosion, particle erosion plus others. This degradation is accelerated due to the high temperatures involved. Some stellite alloys, such as Stellite 31, Stellite 6, Stellite 6B, Stellite 3 and Stellite 19, are used in order to increase the life of certain aircraft engine components [11]. Parts produced using the above-mentioned stellites are flare castings, spacer sleeves, rod end bearings, ball bearings, bearing races, fuel nozzles, swirlers, washers, engine vanes, bearing supports and other static structural parts. Stellite 21 and Stellite 31 alloys are used for producing cast turbine blades which are used in military piston engines on a number of aircraft.

\section{Medical Implants, Ancillary and Instrumentation}

Stellites are extensively used in medical equipment by virtue of their wear resistance and corrosion resistance. Another auxiliary purpose of stellites invented by Haynes was to produce cutlery, surgical and dental instruments, sharp-edged tools which have to be anticorrosive for easy cleaning and to keep the sharpness for the longer periods of time essential for surgical purposes. For surgical tools stellites are used for scissor inserts, needle-holder inserts and other surgical tools. Stellites, and to a larger extent Ti-alloys, have huge, and in some cases unique, industrial and biomedical applications summarized below. These days cobalt and nickel-based alloys are used to produce dental prostheses which are economically cheaper than gold and silver-based alloys but provide adequate quality. Kennametal Stellite produces various dental stellites for making dental crowns, bridges and dentures [3]. As stated, these are their $\mathrm{CoCr}$ and $\mathrm{NiCr}$ alloys they produce for the dental industry.

In biomedical applications metallic biomaterials are used for manufacturing of $70-80 \%$ of implants. In implant manufacturing cobalt-based alloys (Co-alloys) are improvements on Ti-alloys by the criterion of biocompatibility [4]. In specific cases Co-alloys perform better than Ti-alloys by virtue of their ductility. Cobalt-chromium alloys (Co$\mathrm{Cr}$ alloys) exhibit the highest wear resistance and higher strength compared with stainless steels and Ti-alloys, though stainless steels have better ductility and cyclic twist strength than Ti-alloys and Co-alloys. On the other hand, Ti-alloys contain Nickel $(\mathrm{Ni})$ which has been recently proven to be toxic for the human body, making these alloys less biocompatible than Co-alloys. Other applications of stellites in human bone replacement and the surgical industry are unicompartmental tibial components, spacer tibial components, rotating tibial components for knee prostheses and press-fit ace tabular cups for hip prostheses.

\section{Other Fields of Application}

Stellites are applied in the nuclear industry, e.g. impeller bearings for slurry pumps operated in nuclear waste tanks. Some products made from cobalt-based alloys are wires, plates and welding electrodes. Stellites are used for making searchlight reflectors for the Navy and are also used for making lathe cutting tools in rare cases.

\section{STELLITE PRODUCTION PROCESSES}

As mentioned earlier, not many publications on the machining of stellites are available except some on precision casting, powder technology with sintering methods, and coating technology using stellites. Stellite alloys are hard, wear and corrosion resistant, but producing stellite products is highly expensive. Appropriate machining processes of stellites other than grinding have not been yet developed. A literature survey proves that a little work has been done on deposition, cladding, welding and spraying $[15,16,17,18]$. Stellites are used in most cases in the form of coating, powder and casting onto stainless-steel or mild-steel substrates. It is also possible to restore worn surfaces of structural and mechanical components to their original features by making stellite coatings. Powder metallurgy processes are advantageously used to produce unique components of machines from stellite alloys.

Various processes of stellite deposition techniques are briefly described below.

\section{Laser Cladding}

In the laser cladding deposition method, powder particles are deposited onto the steel plate, and the powder is melted by the laser beam before reaching the surface. One, two or five consecutive layers are produced; samples are displayed below in Figure $1[15,18]$. Surface treatment adds value to the products. This process is used for both used and new surfaces to revitalise the worn or damaged surfaces as well as to improve the surface quality for new products. The dimensional accuracy obtained with this method is low. Therefore it becomes necessary to lay down larger amounts of filling materials than are actually needed and then the surface is ground and if necessary polished. This makes the production highly expensive. 
Plasma Transfer Arc (PTA)

As Figure 2 shows, the specimen is placed under a plasma torch and the plasma jet uniformly traversed above the pre-placed layer. After cladding by this system, the specimen has to be slowly cooled down to avoid cracking during the cooling stage [15]. Sodium water glass is used as binder for a pre-placed layer in this process. As a part of their research project on cutting parameter optimisation for Stellite 6 , Hasan et al $[19,20,21,22]$ produced Stellite 6 samples by the powder deposition method onto steel substrates using a Plasma Transfer Arc (PTA) system as shown in Figures 3 and 4. The steel substrate of AISI 4140 was preheated to $260^{\circ} \mathrm{C}$ using an oxyacetylene torch and allowed to soak to an average preheat temperature of $150^{\circ} \mathrm{C}$ prior to deposition. As shown in Figure 3, the Stellite 6 powder was deposited at a rate of $11.5 \mathrm{gm} / \mathrm{min}$ using the PTA system at $120 \mathrm{~A}$ and $26.2 \mathrm{~V}$, while the bar was rotated at $1.5 \mathrm{rpm}$ and the PTA bead was moved along the bar at a pitch of approximately $8 \mathrm{~mm}$ to provide a continuous layer of Stellite 6 on the bar of approximately $250 \mathrm{~mm}$ length. Four bars of Stellite 6, for machining experiments, were produced in this manner, with three bars having a single layer of stellite and one bar having two layers of stellite. One of the problems with a single layer of stellite is that dilution of the stellite by the predominantly iron substrate tends to alter the properties of the material, whereas the outer layer of the two-layer system will have significantly less dilution.

\section{Sintering}

This is a method of producing machine parts from powder materials by compacting the powder in a mould and then heating the compressed parts in a sintering furnace. Sintering strengthens the bonds between the powder metal particles. The sintering process is carried out in two ways. In one way, one of the constituents of the compact melts and in the other way the constituents of the compact do not melt. For example, sintering of cemented carbide is done above the melting point of the cobalt constituent. Carbon atoms appear to dissolve into the cobalt at points of high energy levels to build bridges between the grains.

As an example for none-melting constituents, sintering of iron, copper or tungsten powder is done at $60 \%$ to $80 \%$ of the melting temperature. The atoms at the points of contact blend together and transfer.

Spark sintering is another method which is carried out by placing loose powder in a die, passing a large current through it, and applying pressure at the same time.

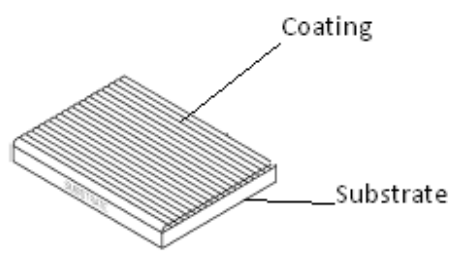

Layer 1

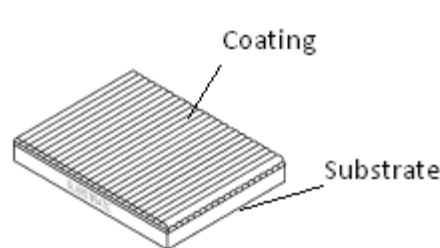

Layer 2

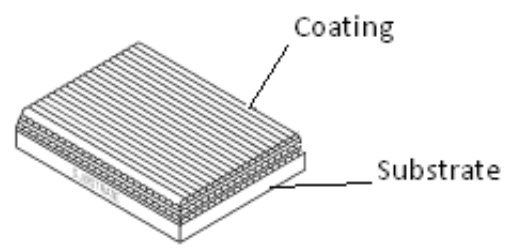

Layer 5

Figure 1: Schematic representation of powder-coated products

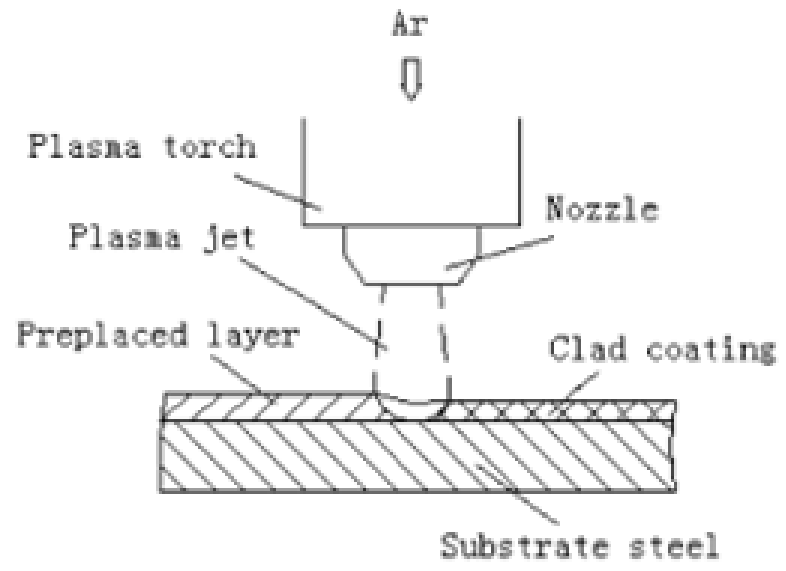

Figure 2: Schematic diagram of plasma arc cladding process 


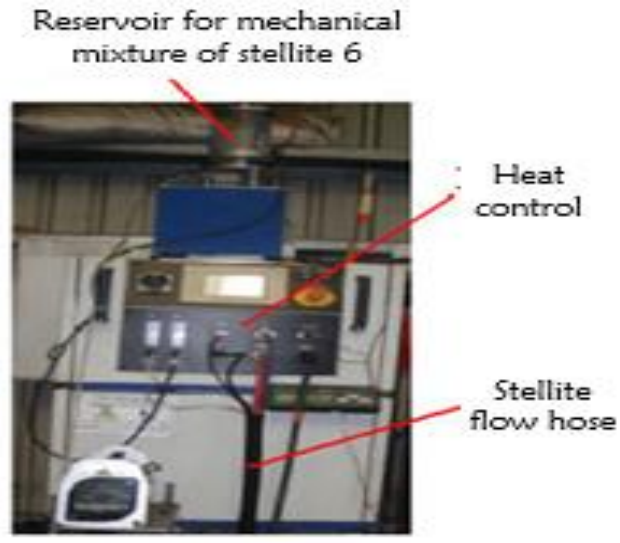

Figure 3: Plasma Arc Cladding Unit

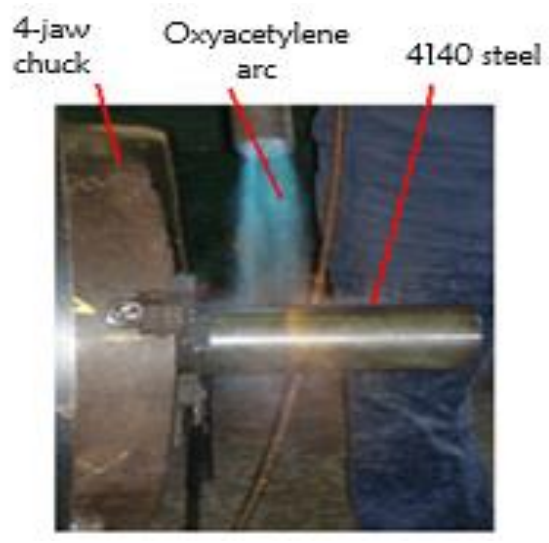

Figure 4: Steel Bar Heating Process

\section{DIFFICULTIES OF STELLITE MACHINING}

As stellite alloys are so hard and tough, it is very difficult to machine them, and as a result parts made of stellite alloys become highly expensive. Generally, items made of stellites are precisely cast, so that minimal machining is required. In most cases, machining is done by grinding rather than by oblique cutting, which is another costly operation. By the nature of their deposition, stellites become difficult-to-machine. The major causes of poor machinability of stellites can be summarized as follows:

- Extremely hard carbides and non-uniform hardness along the surface due to non-homogeneous distribution of carbides;

- Non-homogeneous crystal structure; cobalt changes to FCC after $421^{\circ} \mathrm{C}$ but at below $421^{\circ} \mathrm{C}$ it appears as a $\mathrm{CPH}$ crystallised structure;

- Hard cobalt-carbide growth in the structure of the machining zone subjected to high heat;

- Possible high-level residual stress development during cooling after deposition;

- Higher carbon content leading to dense carbide formation, making stellites have a relatively low thermal conductivity creating a relatively higher temperature in the cutting zone;

- Possible blow hole (micro and nano level) growth in the bulk material during stellite deposition.

As mentioned earlier, a number of Stellite 6 bars were produced using the plasma transfer arc (PTA) method in this research. These stellite bars were used as sample work-pieces for a machinability study $[19,20,21,22]$. The main theme of the current research was concentrated on optimal or rational cutting regimes (speed, feed rate, and depth of cut) development for Stellite 6 that can achieve the least possible surface roughness for machining of Stellite 6 using coated and uncoated carbide cutting tools but not compromising the geometric and surface quality and surface integrity. To prove that the newly developed optimal/rational cutting regimes are worthwhile, further research has been carried out to study the performance of the optimal cutting regimes in respect of the surface integrity, specifically the residual stress level developed in the machined sub-layer as a result of machining processes using the developed optimal cutting regimes for Stellite 6 .

The current authors also examined and analysed the microhardness at various depths of the machined layer of Stellite 6. This study gives an understanding of hardness variation, at various depths along and across the tested specimen, under the effect of the cutting forces and heat generated in the cutting zone. The heat generated in the cutting zone is capable of changing the metallographic phase, as well as the hardness, of machined surfaces. Evidently there is a correlation between the residual stress level and the hardness of metal components.

\section{RESIDUAL STRESS DEVELOPMENT}

In the process of external static or dynamic loading (mechanical or thermal), materials are subjected to stresses. After removing the loading most of the stresses may be released but some portion of the stresses persists in the crystal lattice of materials and is called residual stress [21, 22, 23, 24, 25]. Residual stresses are induced in sub-layers of machined surfaces due to the action of the cutting forces exerted by primary and auxiliary cutting motions which cause plastic deformation of the surface material during the machining processes. The heat generated in the cutting region is another major cause of residual stress development on the sub-layer of the machined surface. As a result of the cutting processes, residual stresses are developed in both longitudinal (direction of feed) and tangential (direction of cut) directions of the machined part. These unwanted residual stresses play a crucial role in the performance of machined parts and their durability. Unfavourable residual stress development may cause 
unacceptable deformation that may prevent the part from meeting the required dimensional tolerances. Residual stresses can also affect the fatigue strength and fatigue life of the components.

In a physical sense the crystal lattice is either compressed or strained in volume due to the residual stresses. Accordingly residual stresses are considered as either compressive (positive) or strained (negative). The work of many researchers has revealed that both kind of residual stresses reside in the metal structure simultaneously, forming a neighbourhood. In metal machining processes the cutting forces, causing plastic deformation at the cutting zone to create chips and subsequently causing high temperature (in some cases up to $2900^{\circ} \mathrm{C}$ ) growth, contribute to the development of residual stresses in the sub-layer of machined surfaces. Researchers agree that residual stresses affect only the upper/outer layer of a component to a depth of up to $500 \mu \mathrm{m}$, while at up to 50$100 \mu \mathrm{m}$ intense values of residual stresses are observed. It is known that the outer surface is more important for machine components in respect of all types of loadings (tensile, bending, moment, shear) as well as for wear and corrosion. That is why the quality and integrity of the outer surfaces of machine components are so crucial. Negative residual stresses contribute to fatigue micro-crack creation as a result of creation (or a tendency to creation) of dislocation in the crystal lattice of machine components. It has been revealed that the residual stresses have a close relationship with the mechanical and metallurgical capabilities of parts, and these affect the phase transformation and topological states of machined parts. Several authors indicate that strained or positive residual stresses may improve the surface integrity of products in certain cases. This is reasonable since it is assumed that the positive residual stress may contribute to some level of compaction of the crystal structure, improving the bonding and reducing or removing the dislocation in the crystal structure. At the same time it is logically understandable that both positive and negative residual stresses appear together in sequence. Therefore a study of residual stress growth phenomena, and mechanical and metallurgical transformation in the sub-layer of machined parts, are equally vital for quality assessment of machined parts as are other parameters such as the surface roughness and geometric accuracy of the machined parts. At present various methods are available to measure residual stresses, such as incremental hole drilling, X-ray diffraction, hard X-rays, neutron diffraction, and ultrasonic waves. It has been revealed that the residual stresses on or in the machined surface greatly affect a part's fatigue life, resistance to cracking, stress corrosion, static strength and magnetic properties [24, 25, 26, 27]. Controlling residual stress development on the machined surface is a prerequisite for the successful application of materials, especially in the aerospace, automotive, nuclear, refinery and mining industries [27, 28].

Pawade et al. established [33] that residual tensile stresses reduce the fatigue strength of machined parts, shortening the legitimate product life. It has been concluded that the residual stresses occur within a depth of 50 $\mu \mathrm{m}$ of the surface if sharp tools are used and up to $500 \mu \mathrm{m}$ if worn tools are used. It has also been found that a build-up of residual strains can cause distortion of thin and/or long work-pieces. Pawade et al. performed an experimental study on residual stress development for Inconel 718 using an X-ray diffractometer method on machined surfaces using machining conditions of high cutting speed $(475 \mathrm{~m} / \mathrm{min})$, low feed rate $(0.05 \mathrm{~mm} / \mathrm{rev})$, medium depth of cut $(0.5 / 0.75 \mathrm{~mm})$ with a honed cutting edge, and they observed compressive residual stresses in sub-layer machined surfaces. Likewise, Hasan et al. found high-tensile residual stress when using a tool nose radius of $0.8 \mathrm{~mm}$, and lower growth of residual stresses was observed at nose radii of $0.4 \mathrm{~mm}$ and $1.2 \mathrm{~mm}[19,20,21$, 22]. Outeiro et al. analysed [30] residual stresses of difficult-to-machine materials like Inconel 718 and Austenitic Stainless Steel AISI 316L along the round profile of the machined bar using X-ray diffraction after machining under various conditions with coated and uncoated cutting tools. They found that the occurrence of residual stresses is higher when machining with uncoated tools than with coated tools. They also found high-tensile residual stresses on the machined surface and compressive residual stresses in the subsurface. This phenomenon supports the proposition that both positive and negative residual stresses appear together. Sailo et al. analysed residual stresses on turbine disks (made of Inconel 718) of jet engines that were machined under various cutting conditions [35]. The tensile residual stresses were measured (ranging up to $800 \mathrm{MPa}$ ) on the disk surface and the authors deduced that these severely affected the life of the turbine disks. Three different depths of cut $(0.06 \mathrm{~mm}, 0.12 \mathrm{~mm}$ and 0.18 $\mathrm{mm}$ ) were selected to investigate the residual stresses. As the graph in Figure 5 shows, the worst condition was at the $0.06 \mathrm{~mm}$ depth of cut because this produced the lowest value of compressive residual stress $(-100 \mathrm{MPa})$ and the highest value of tensile residual stress $(800 \mathrm{MPa})$ [35]. The lowest tensile residual stress (500 MPa) was at the 0.18 $\mathrm{mm}$ depth of cut.

It has been concluded that the residual stresses are one of the important parameters for measuring the quality and reliability levels of the machined surfaces and are more influential when machining critical structural components, which are widely used in nuclear power generation and in the aerospace industry [30, 32]. Furthermore, residual stresses are a design factor for design engineers, especially for components for aerospace, nuclear and other critical engineering industries. Component life is seriously shortened by residual stress development during machining. Residual stresses may develop because of peening, machining, cold hole expansion, bending, welding, thermal stresses, and loading stresses. It can be seen that residual stress is an important parameter which can help to predict product life, quality and reliability. As mentioned it is a key parameter for design engineers and is a significant factor to consider when critical structural components are designed and manufactured, particularly for nuclear power generation and the aerospace industry. 


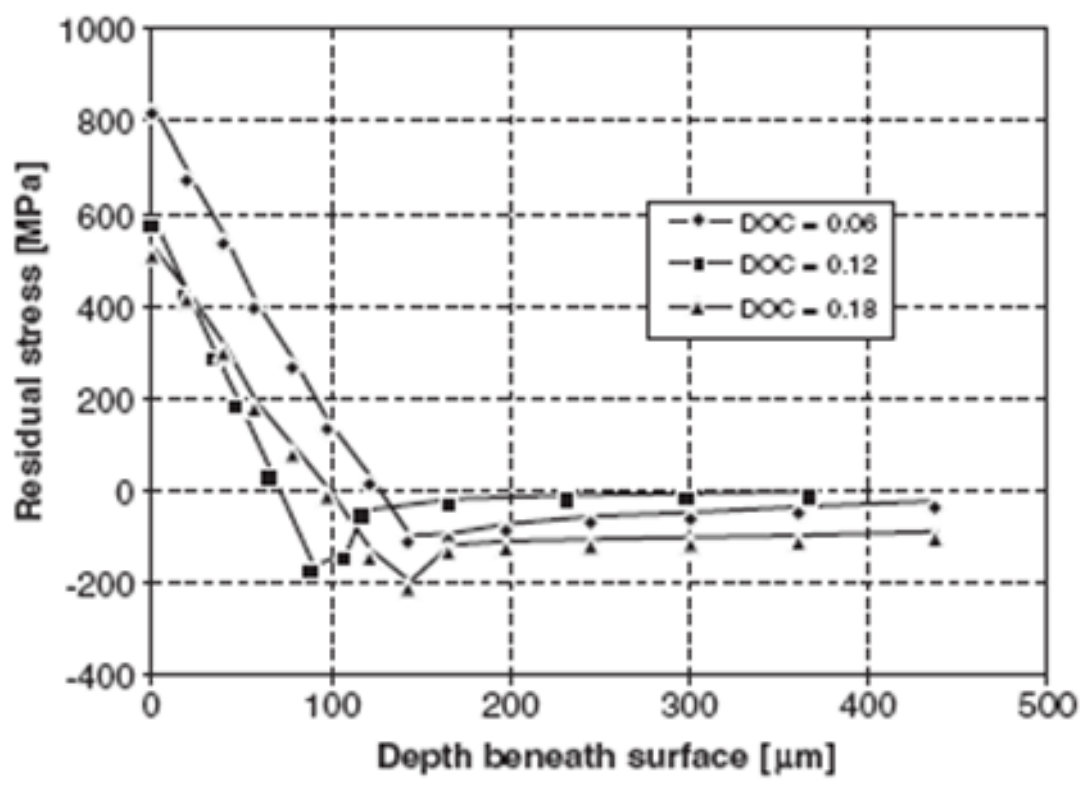

Figure 5: Residual stresses at different depths of cut

\section{SURFACE ROUGHNESS AND RESIDUAL STRESS}

Stellite 6 is a highly regarded engineering alloy and it has, as mentioned earlier, high heat resistance, corrosion resistance and wear resistance. As far as is known adequate machining techniques and processes have not yet been developed for Stellite 6 other than that for grinding. A limited number of studies has been noticed in areas of machining of this valuable super alloy. Ohtani et al. performed turning operations on Stellite 6 using carbide inserts and $C B N$ inserts and various cutting speeds, and found better values of surface roughness $\left(R_{a}\right)$ of $3.5 \mu \mathrm{m}$ at 200 $\mathrm{m} / \mathrm{min}$ cutting speed for $C B N$ inserts and $4 \mu \mathrm{m}$ at $30 \mathrm{~m} / \mathrm{min}$ for carbide inserts [37]. The authors did not examine the effect of feed rate, depth of cut and tool nose radius on surface roughness. They also did not analyse the changes of surface properties of machined samples such as residual stress, microstructural changes and microhardness development on the machined surface. They did not analyse the chemical composition of the machined surface.

Recently, the current authors (Hasan et al.) carried out $[19,20,21,22]$ a series of machining (turning) experiments on Stellite 6 PTA bars using titanium-nitride-coated inserts (Figure 6: a, b, c) with various nose radii $(0.4 \mathrm{~mm}, 0.8 \mathrm{~mm}$ and $1.2 \mathrm{~mm})$, as shown in Figure 6, on a Harrison M400 lathe. Other geometric parameters of these inserts are rake angle $-6^{\circ}$, inclination angle $-6^{\circ}$, lead angle $95^{\circ}$, clearance angle $0^{\circ}$, nose angle $80^{\circ}$. The results of the experiments are shown in the graphs in Figures 7 and 8. The graph in Figure 7 shows the variation of surface roughness obtained for different nose radii of the coated carbide inserts. It suggests that the use of cutting inserts with a higher nose radius reduces the surface roughness. A series of experiments was performed and it was found that the optimal tool nose radius for coated carbide inserts (for machining Stellite 6 ) is $0.8 \mathrm{~mm}$, which produced the best surface within the range of surface roughness $R_{a}=0.6 \mu \mathrm{m}-1 \mu \mathrm{m}$ for variable cutting speed, feed rate and depth of cut.

Initially the optimal cutting parameters (speed, feed rate, depth of cut) for Stellite 6 machining using different nose radii of coated carbide inserts to obtain the lowest value of surface roughness were established by a series of real-life experiments $[19,20,21,22]$. The established optimal machining parameters to achieve the best surface roughness for machining Stellite 6 using coated carbide inserts with various nose radii are recorded in Table 3 . Moreover, Hasan et al. experimented on and analysed $[19,20,21,22]$ the residual stress development in a machined surface of a Stellite 6 bar using coated carbide inserts with three different nose radii $(0.4 \mathrm{~mm}, 0.8 \mathrm{~mm}$ and $1.2 \mathrm{~mm}$ ); the results obtained are shown graphically in Figure 8. Investigations with Stellite 6 revealed that the measured values of residual stresses on the machined surface are lower for $0.4 \mathrm{~mm}$ and $1.2 \mathrm{~mm}$ nose radii (of coated carbide inserts) for both axis parallel and axis perpendicular X-ray deflection (XRD) methods as shown in Figure 8. However, the stress values are comparatively higher for samples machined using a $0.8 \mathrm{~mm}$ nose radius of cutting tools. It has been observed that the maximum values of residual stress are $660 \mathrm{MPa}$ and $300 \mathrm{MPa}$ of strain for axis parallel and perpendicular directions respectively.

The series of experimental investigations revealed the surprising fact that use of cutting tools with lower and higher nose radii for machining Stellite 6 provides better results in the sense of residual stresses induced by the machining process, while a cutting tool with medium nose radius $(0.8 \mathrm{~mm})$ provides worse strain residual stress. 
Eventually, this may cause premature micro-crack initiation in sub-layers of components, which, in turn, reduces the fatigue life of products. The effect of machining or grinding will often produce a compressive residual stress in the surface of a component. Guidance in the standard HS-784 Residual Stress Measurement by X-ray Diffraction indicates that even if a sample is mechanically polished to a $1 \mu \mathrm{m}$ metallographic finish, $x$-ray diffraction measurements typically measure a $50 \mathrm{MPa}$ compressive residual stress induced by the polishing process, regardless of the underlying residual stress state. Compressive residual stresses in the measurements here are therefore not unexpected, even though it is expected that the underlying residual stress state in the weld will be tensile in nature.

Table 3: Optimal machining parameters for Stellite 6 using coated carbide tools

\begin{tabular}{|c|c|c|c|}
\hline \multirow{2}{*}{$\begin{array}{c}\text { Nose radius } \mathrm{N}_{\mathrm{r}} \\
{[\mathrm{mm}]}\end{array}$} & \multicolumn{3}{|c|}{ Optimal machining parameters } \\
\cline { 2 - 4 } & Cutting speed $\mathrm{V}[\mathrm{m} / \mathrm{min}]$ & Feed rate $\mathrm{f}[\mathrm{mm} / \mathrm{rev}]$ & Depth of cut $\mathrm{d}[\mathrm{mm}]$ \\
\hline 0.4 & 50 & 0.08 & 1.6 \\
\hline 0.8 & 80 & 0.1 & 0.3 \\
\hline 1.2 & 50 & 0.1 & 0.8 \\
\hline
\end{tabular}

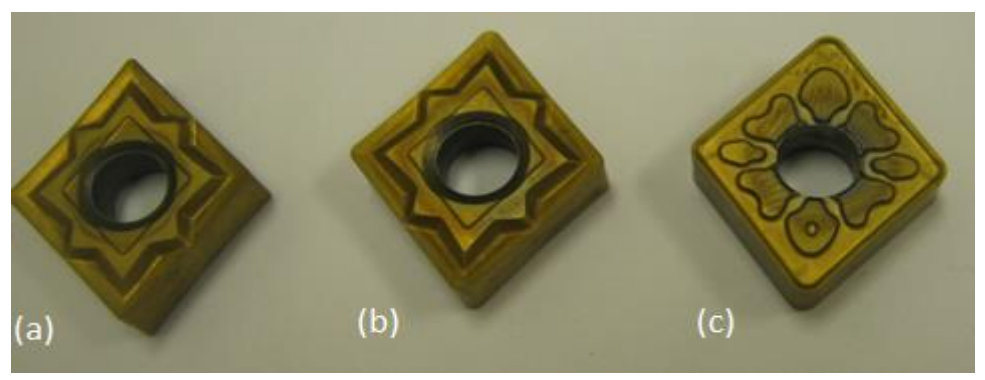

Figure 6: Coated carbide inserts

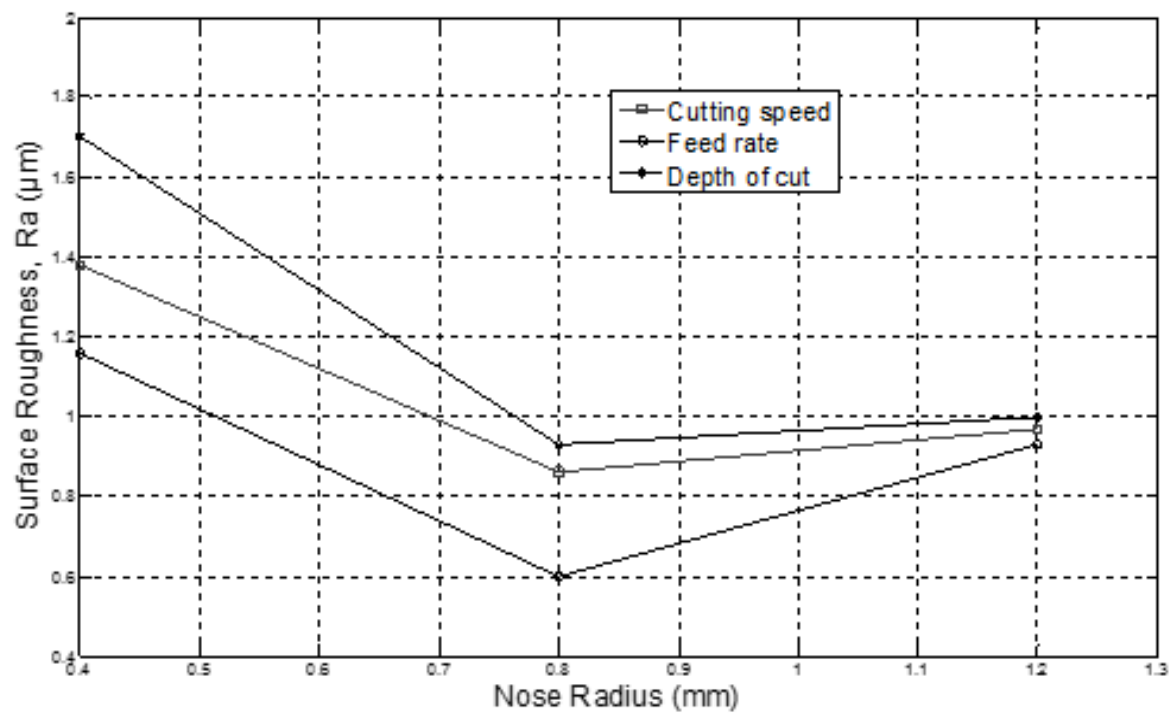

Figure 7: Influence of nose radius on surface roughness 


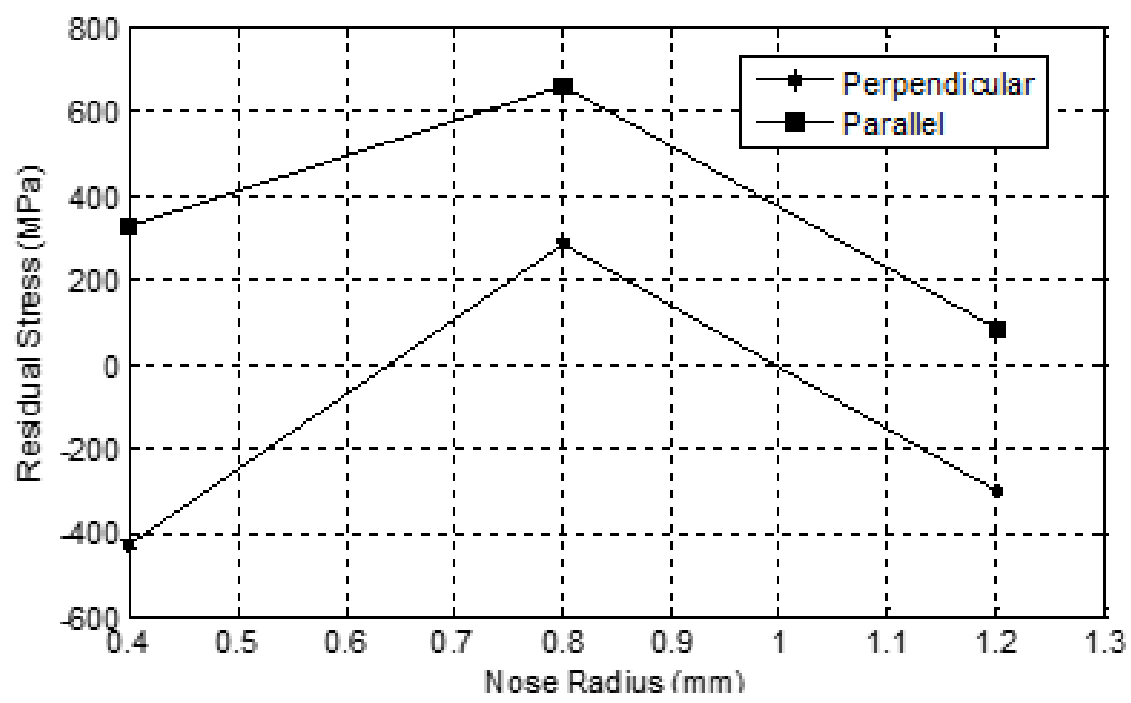

Figure 8: Residual stresses, different nose radii, coated carbide

\section{MICRO-HARDNESS VARIATION ON MACHINED SURFACES}

Residual stresses affect the hardness of the machined surface. Also during machining the cutting zone of the workpiece is deformed plastically, causing work hardening of the machined surfaces. The micro-hardness in the machined surface region changes from the original hardness of the work-piece under all cutting conditions due to non-uniform heat generation and rapid cooling of the work-piece. As reported in [19], the author investigated the microhardness at various depths (up to about $500 \mu \mathrm{m}$ ) of a machined surface of Stellite 6 that was machined by coated carbide inserts of three different nose radii $(0.4 \mathrm{~mm}, 0.8 \mathrm{~mm}$, and $1.2 \mathrm{~mm})$. The microhardness at different points located at different depths of the machined surfaces was tested using a Vickers Hardness Tester, model $\mathrm{MH}-$ 5. The results of the microhardness assessments are shown in graphical form in Figure 9. The newly obtained optimal cutting parameters $[19,20,21,22]$ were used for preparing the samples for microhardness testing. This helped to assess the surface integrity of the newly established optimal cutting parameters for rational machining of Stellite 6.

As can be seen from the graph in Figure 9, the surface microhardness is lower (39.6 HRC) at minimum depth for a sample which was machined using a $0.8 \mathrm{~mm}$ nose radius, and the microhardness values increase up to 48 $\mathrm{HRC}$ at $0.225 \mathrm{~mm}$ depth with increasing depth underneath the machined surface. For other samples produced using coated carbide inserts with $0.4 \mathrm{~mm}$ and $1.2 \mathrm{~mm}$ nose radii, the values of microhardness fluctuate slightly at various depths under the machined surface. Higher values of microhardness have been observed on machined surfaces generated using a coated carbide insert with a $1.2 \mathrm{~mm}$ nose radius, and values increase with depth up to $0.25 \mathrm{~mm}$. Finally a downward tendency is found at large depth for all three samples. It is assumed that a small nose radius $(0.4 \mathrm{~mm})$ means that the sharp tool tip concentrates the cutting forces in a small area, which increases the strain on the machined surface. This causes a higher temperature in a small area and leads to hardness variations in the machined surface. On the other hand, a larger nose radius $(1.2 \mathrm{~mm})$ increases the cutting forces and produces more heat in the cutting zone. This heat causes plastic deformation and affects the surface hardness.

\section{METALLOGRAPHY OF MACHINED SURFACE}

As been discussed above, there are changes in the residual stresses and microhardness of the machined surfaces, so changes in the metallographic microstructure have been observed in the investigation. A typical metallographic microstructure of a machined Stellite 6 surface is presented in Figure 10. The surface was produced $[19,20,21,22]$ by machining of Stellite 6 PTA using a coated carbide cutter and the optimal cutting regimes $V=50 \mathrm{~m} / \mathrm{min}, \mathrm{f}=$ $0.08 \mathrm{~mm} / \mathrm{rev}, \mathrm{d}=1.2 \mathrm{~mm}$ and nose radius $=0.4 \mathrm{~mm}$. The microstructure shows non-homogeneous carbide formation after the machining process. A series of experiments has revealed that the carbide formation is very different for samples machined with different cutting regimes. It appears that non-homogeneous hard carbide affects the surface roughness of the machined surfaces, which leads to rapid tool wear. It was also found that microstructural changes occurred due to the machining of Stellite 6 using coated carbide inserts, because at and beyond $421{ }^{\circ} \mathrm{C}$ cobalt itself appears in a FCC crystal lattice structure rather than the CPH structure which exists below $421^{\circ} \mathrm{C}$. As mentioned earlier the samples of Stellite 6 bars were produced using the plasma transfer arc (PTA) system by depositing a Stellite 6 homogeneous mixture at the home of a local company. The composition used for manufacturing these sample bars agrees with the standard composition given in Table 1. 


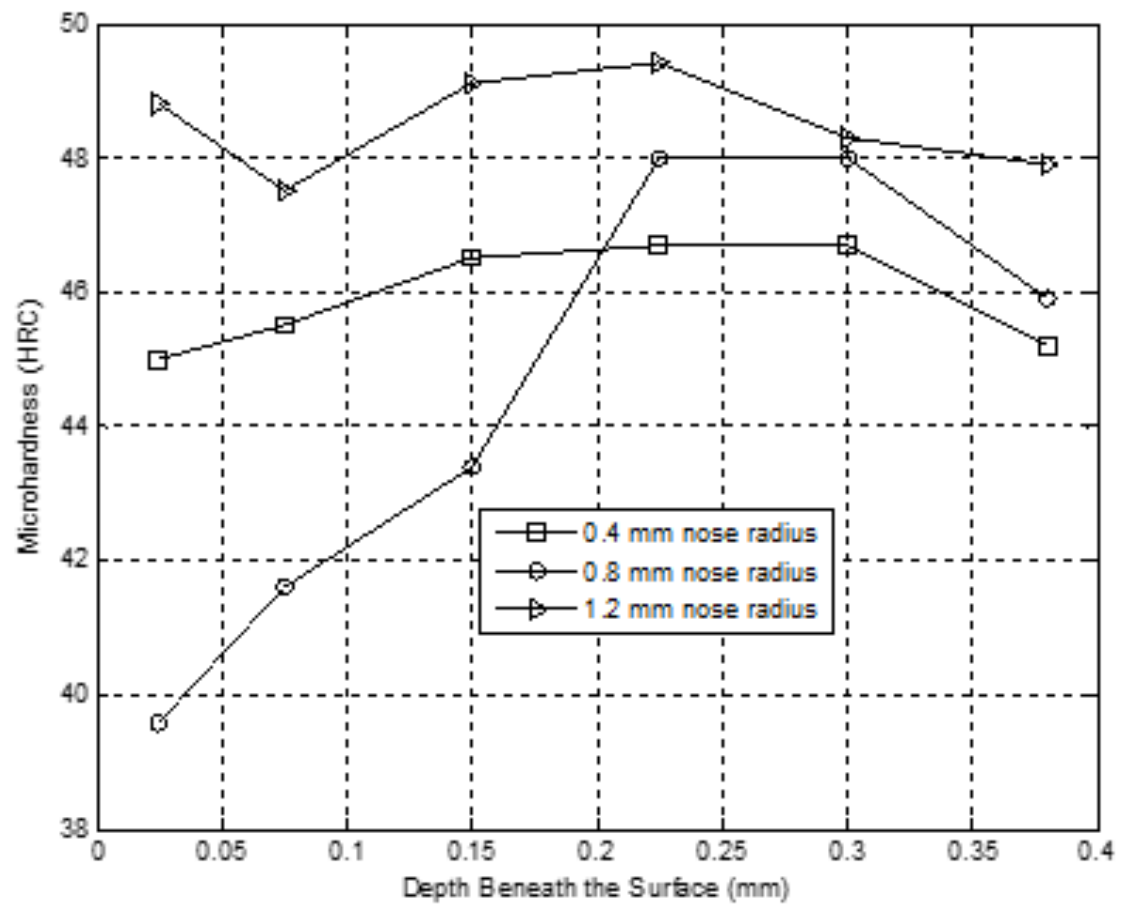

Figure 9: Microhardness of machined surface of Stellite 6 (using coated Carbide inserts)
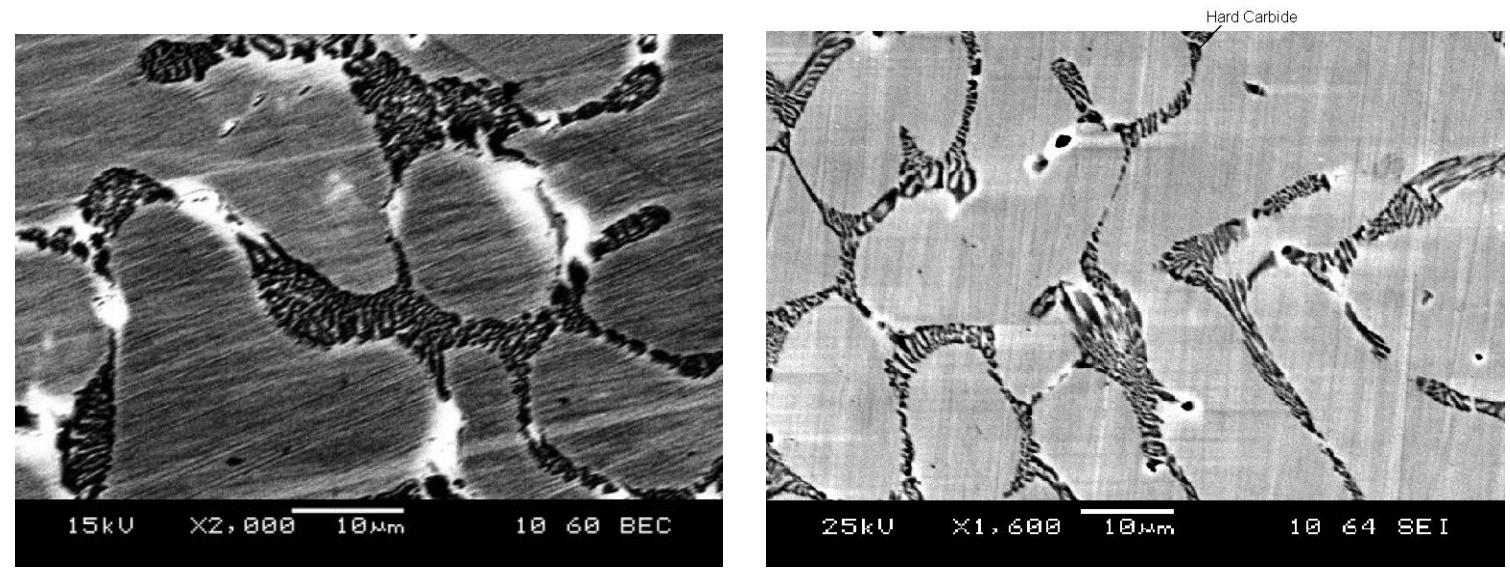

Figure 10: Metallographic microstructure of Stellite 6

In other works, the current authors performed a series of experiments $[19,20,21,22]$ using the manufactured samples of Stellite 6 PTA for optimisation of cutting regimes for Stellite 6 using coated and uncoated carbide cutting tools, PCBN (poly-carbide boron nitride) and other advanced cutting tool materials by the way of real-life experiments. The surface integrity obtained after machining using the newly developed optimal cutting parameters/regimes has been also assessed and analysed.

\section{CONCLUSION}

This paper has attempted to provide an analysis of the superior and useful properties of stellites, a group of cobaltbased super alloys. It has focussed on specific applications of various grades of stellites, their mechanical and metallurgical properties and chemical compositions for many mechanically critical parts used in oil and gas industries, chemical refineries and the petrochemical industry, mining, pulp and paper industries, food processing 
industry, wood and timber industry, automotive and aerospace industries. It is believed that this paper will be an excellent and valuable source of basic but most essential information for researchers, scientists, engineers and professionals dealing with cobalt-based alloys. Moreover this paper has attempted to briefly describe the applications of some ductile and low-magnetic-permeability cobalt alloys in dental implants and human bone replacements, manufacture of artificial heart valves and heart pacemakers. This scope may be further extended in another paper. Chemical compositions and mechanical properties have also been collected in a table format for easy use for particular applications.

There is a good prospect to improve the machining technique and the technology of stellites to overcome the machining difficulties. As parts made of stellites are widely used in various industries and very popular in specific applications, it is a big drawback that adequate machining processes for stellites have not yet been developed other than the costly and time-consuming technique of grinding. However, an attempt has been made to reveal the optimal machining parameters (cutting speed, feed rate and depth of cut) for a lower value of surface roughness for the purpose of successful machining of Stellite 6 using new grades of coated and uncoated carbide inserts with various nose radii $(0.4 \mathrm{~mm}, 0.8 \mathrm{~mm}$ and $1.2 \mathrm{~mm})$. The observed phenomena relative to the machinability of Stellite 6 are found to be directly related to the properties of stellites.

An experimental study on residual stress growth on a machined surface of Stellite 6 was performed in perpendicular and parallel to the directions of the axis of the machined bar. Compressive residual stresses are observed (- $400 \mathrm{MPa}$ and $-300 \mathrm{MPa}$ ) for the nose radii of $0.4 \mathrm{~mm}$ and $1.2 \mathrm{~mm}$. The residual stresses induced by the effect of the cutting process would have been superimposed on the residual stresses in the underlying weld structure, which are expected to be tensile and of a similar value to the yield stress of the stellite (approximately $600 \mathrm{MPa}$ ). The specimens machined using cutting tools with 0.4 and $1.2 \mathrm{~mm}$ tip radii appear to be more effective in masking the underlying residual stress state than the $0.8 \mathrm{~mm}$ tool tip. However, if compressive residual stresses can be induced in the surface of a component by manipulating machining parameters, this may be an effective way of reducing phenomena such as stress corrosion cracking and fatigue.

From these experiments, it was found that cutting inserts with a $0.8 \mathrm{~mm}$ nose radius produced better values of surface roughness (Figure 7) than with nose radii of $1.2 \mathrm{~mm}$ and $0.4 \mathrm{~mm}$. However, $1.2 \mathrm{~mm}$ and $0.4 \mathrm{~mm}$ nose radii caused comparatively lower residual stress (Figure 8 ) in the machined surface. A literature search found that not much has been published in relation to machining of stellites. Stellites are useful for special purposes by virtue of their excellent physico-mechanical properties. Due to their poor machinability stellites have been catagorised as difficult-to-machine materials. It is worthwhile to carry out more vigorous research on the machining and machinability of stellites for development of better machining processes and economically sustainable optimal machining parameters but not compromising the product quality and surface integrity of the machined products.

\section{ACKNOWLEDGEMENTS}

The authors acknowledge the contribution of Gary Hoare at Central Queensland University Australia and Berg Engineering, Queensland, Australia for their generous help in experiments.

\section{REFERENCES}

1. Sponaugle, C. (2005). History of Hynes International Inc., Pittsburgh Engineer. Quarterly publication of the Engineers' Society of Western Pennsylvania Winter, 7-9.

2. Dhokia, S. V., \& Newman, S. T. (2012). Environmentally conscious machining of difficult-to-machine materials with regard to cutting fluids. International Journal of Machine Tools and Manufacture, 57, 83-101.

3. Marti, A. (2000). Cobalt-base alloys used in bone surgery. Injury, International Journal of the Care of the Injured, 31(4), 18-21.

4. Niinomi, M., Nakai, M., \& Heida, J. (2012). Development of new metallic alloys for biomedical applications. Acta Bimaterialia, 8, 3888-3903.

5. Shao, H., Li, L., Liu, L. J., \& Zhang, S. Z. (2013). Study on machinability of a stellite alloy with uncoated and coated carbide tools in turning, Journal of Manufacturing Processes, (15), 673-681.

6. ASM Handbook. (2009). Retrieved from http://products.asminternational.org/hbk/index.jsp.

7. Yao, M. X., Wu, J. B. C., \& Xie, Y. (2005). Wear, corrosion and cracking resistance of some W- or Mocontaining stellite hard-facing alloys, Material Science and Engineering A, 407, 234-244.

8. Das, C. R., Albert, S. K., Bhaduri, A. K., \& Kempulraj, G. A. (2003). Novel procedure for fabrication of wearresistant bushes for high-temperature application, Journal of Materials Processing Technology, 141, 60-66.

9. Deloro Stellite Inc. (2009). Retrieved from www.stellite.com.

10. Bagci, E., \& Aykut, S. A. (2006). Study of Taguchi optimization method for identifying optimum surface roughness in CNC face milling of cobalt-base alloy (stellite 6), International Journal of Advanced Manufacturing Technology, 29, 940-947.

11. Sims, C. T. (1972). Cobalt-Base Alloys, the Superalloys, John Wiley and Sons, 145.

12. Yao, M. X., Wu, J. B. C., Xu, W., \& Liu, R. (2005). Metallographic study and wear resistance of a high-C wrought Co-based alloy Stellite 706K. Materials Science and Engineering: A, 407, 291-298. 
13. Ruml, Z., \& Straka, F. A. (1995). New model for steam turbine blade materials erosion. Wear, 186-187, 421424.

14. Zhao, C., Tian, F., Peng, H. R., \& Hou, J. Y. (2002). Non-transferred arc plasma cladding of stellite Ni60 alloy on steel. Surface and Coatings Technology, 155(1), 80-84.

15. Fouilland, L., El Mansori, M., \& Gerland, M. (2007). Role of welding process energy on the microstructural variation in a cobalt-based superalloy hardfacing. Surface and Coating Technology, 201, 6445-6451.

16. Barsoum, Z., \& Lundback, A. (2009). Simplified FE welding simulation of fillet welds - 3D effects on the formation of residual stresses. Engineering Failure Analysis, 16(7), 2281-2289.

17. Xueping, Z., Erwei, G., \& Liu, C. R. (2009). Optimisation of process parameter of residual stresses for hard turned surfaces. Journal of Materials Processing Technology, 209, 4286-4291.

18. Kaul, R., Ganesh, P., Tiwari, M. K., Singh, A. K., Tripathi, P., Gupta, A., \& Nath A. K. (2002). Laser assisted deposition of graded overlay of Stellite 6 on austenitic stainless steel. Laser in Engineering, 12(3), 207-225.

19. Hasan, M. S., Mazid, A. M., \& Clegg, R. E. (2010). Optimisation of the machining of stellite 6 PTA hardfacing using surface roughness. Key Engineering Materials, 443, 227-231.

20. Hasan, M. S., Mazid, A. M., \& Clegg, R. E. (2010). Effect of cutting tool nose radius on surface roughness for Stellite 6 machining using coated carbide insert. In Proc. of the 6th Australian Congress on Applied Mechanics (ACAM 6 2010), Perth, Australia, 603-612.

21. Hasan, M.S., Mazid, A. M., Clegg, R. E., \& McLeod, A. (2010). Residual stress analysis on machined surface in turning Stellite 6. In Proc. of the 6th Australian Congress on Applied Mechanics (ACAM 6 2010), Perth, Australia, 714-722.

22. Hasan, M. S. (2011). Optimisation of machining processes design for stellite 6 , a wear resistant and difficult-tomachine material. Master of Engineering thesis, Central Queensland University, Rockhampton, Australia, 136.

23. Hamiuddin, M. (1987). Development of wear resistant strong and fully dense stellite by liquid phase sintering. Powder Metallurgy International, I 19(2), 22-26.

24. D'Oliveira, A. S. C. M., Da Silva, P. S. C. P., \& Vilar, R. M. C. (2002). Microstructural features of consecutive layers of stellite 6 deposited by laser cladding. Surface and Coatings Technology, 153(2-3), 203-209.

25. Guo, Y. B., Li, W., \& Jawahir, I. S. (2009). Surface integrity characterization and prediction in machining of hardened and difficult-to-machine alloys: A state-of-art research review and analysis. Machining Science and Technology, 13, 437-470.

26. Arrazola, P. J., Ozel, T., Umbrello, D., Davies, M., \& Jawahir, I. S. (2013). Recent advances in modelling of metal machining processes. CIRP Annals - Manufacturing Technology, 62(2), 695-718.

27. Jawahir, S., Brinksmeier, E., M'Saoubi, R., Aspinwall, D. K., Outeiro, J. C., Meyer, D., Umbrello, D., \& Jayal, A. D. (2011). Surface integrity in material removal processes: Recent advances. CIRP Annals - Manufacturing Technology, 60, 603-626.

28. Brinksmeier, E., Cammett, J. T., Kbnig, W., Leskovar, P., Peters, J., \& Tonshoff, H. K. (1982). Residual stresses measurements and causes in machining processes, Annals of the CIRP, 31(2), 491-510.

29. Jang, D. Y., Watkins, T. R., Kozaczek, K. J., Hubbard, C. R., \& Cavin, O. B. (1996). Surface residual stresses in machined austenitic stainless steel, Wear, 194, 168-173.

30. Wu, D. W., \& Matsumoto, Y. (1990). The effect of hardness on residual stresses in orthogonal machining of AISI 4340 steel. Trans, of the ASME, J. of Engineering for Industry, 112(3), 245-252.

31. Hua, J., Shivpuri, R., Cheng, X., Bedekar, V., Matsumoto, Y., Hashimoto, F., \& Watkins, T. R. (2005). Effect of feed rate, workpiece hardness and cutting edge on subsurface residual stress in the hard turning of bearing steel using chamfer + hone cutting edge geometry. Material Science and Engineering A, 394, 238-248.

32. Wang, Y. D., Peng, R., Wang, X. L., \& McGreevy, R. L. (2002). Grain orientation-dependent residual stress and the effect of annealing in cold-rolled stainless steel. Acta Materialia, 50, 1717-1734.

33. Pawade, R. S., Joshi, S. S., \& Brahmankar, P. K. (2008). Effect of machining parameters and cutting edge geometry on surface integrity of high-speed turned Inconel 718. International Journal of Machine Tools and Manufacture, 48, 15-28.

34. Outeiro, J. C., Pina, J. C., M'Saoubi, R., Pusavec, F., \& Jawahir, I. S. (2008). Analysis of residual stresses induced by dry turning of difficult-to-machine materials, CIRP Annals - Manufacturing Technology, 57, 77-80.

35. Salio, M., Berruti, T., \& De Poli, G. (2006). Prediction of residual stress distribution after turning in turbine disks. International Journal of Mechanical Sciences, 48(9), 976-984.

36. Withers, P. J., \& Bhadeshia, H. K. D. H. (2001). Residual stress Part 1 - Measurement techniques. Material Science and Technology, 17, 355-365.

37. Ohtani T., Fujise, K., \& Yokogawa H. (1988). Machining of stellite alloy with CBN and carbide tools, Reports of the Government Industrial Institute, Chugoku (J) Publisher, 30.

38. Seco technical guide. (2009). Turning difficult-to-machine alloys. 240.

39. Radu, I., \& Li, D. Y. (2007). The wear performance of yttrium-modified Stellite 712 at elevated temperature. Tribology International, 40, 254-265.

40. Ning, Y., Patnaik, P. C., Liu, R., Yao, M. X., \& Wu, X. J. (2005). Effects of fabrication process and coating of reinforcements on the microstructure and wear performance of stellite alloy composites. Material Science and Engineering: A, 391(1-2), 313-324. 
41. Costa, J. M., Pires, J. T. B., Antunes, F., Nobre, J. P., \& Borrego, L. P. (2010). Residual stresses analysis in NDYAC laser welded joints. Engineering Failure Analysis, 17(1), 28-37.

42. Doyle, L., Keyser, C. A., Leach, J. L., Schrader, G. F., \& Singer, M. B. (1985). Manufacturing Processes and Materials for Engineering, Third Edition, Prentice-Hall, Inc., Englewood Cliffs, New Jersey. 926.

43. Yao, M. X., Wu, J. B. C., Xu, W., \& Liu, R. (2005). Metallographic study and wear resistance of a high-C wrought Co-base alloy stellite 706K. Materials Science and Engineering: A, 407, 291-298.

44. Cinca, N., Lopez, E., Dosta, S., \& Guilemany, J. M. (2013). Study of stellite-6 deposition by cold gas spraying. Surface and Coating Technology, 232, 891-898.

45. Martin, C. L. (2007). Alloys go with the grain (Material Science). Nature, 445, 34-35.

46. Benghersallah, M., Boulanouar, L., Le Coz, G., Devillez, A., \& Dudzniski, D. (2010). Machinability of stellite 6 hardfacing. EPJ Web of Conferences 6, 02001 DOI:10.1051/epjconf/20100602001. 